\title{
BMJ Open Use of complementary medicine products: a nationally representative cross-sectional survey of 2019 Australian adults
}

\author{
Joanna E Harnett, ${ }^{\oplus 1}$ Erica Mclntyre, ${ }^{2}$ Amie Steel, ${ }^{3}$ Hope Foley, ${ }^{4}$ David Sibbritt, ${ }^{5}$ \\ Jon Adams ${ }^{5,6}$
}

To cite: Harnett JE, McIntyre E,

Steel A, et al. Use of complementary medicine products: a nationally representative crosssectional survey of 2019 Australian adults. BMJ Open 2019;9:e024198. doi:10.1136/ bmjopen-2018-024198

- Prepublication history for this paper is available online. To view these files, please visit the journal online (http://dx.doi. org/10.1136/bmjopen-2018024198).

Received 29 May 2018 Revised 12 March 2019 Accepted 12 June 2019

Check for updates

(C) Author(s) (or their employer(s)) 2019. Re-use permitted under CC BY-NC. No commercial re-use. See rights and permissions. Published by BMJ.

For numbered affiliations see end of article.

Correspondence to Dr Joanna E Harnett; joanna.harnett@sydney.edu.au

\section{ABSTRACT}

Objectives To provide a contemporary description of complementary medicine (CM) product use in Australia. Design Cross-sectional survey.

Setting Online.

Participants A nationally representative sample $(n=2019)$ of the Australian adult population.

Primary and secondary outcome measures Primary outcomes measures included the use and type of CM products used, and source of recommendation. Secondary measures included disclosure of CM product use to health practitioners, concomitant use of pharmaceuticals and predictors of use.

Results Prevalence of CM product use was $50.3 \%$, with the most frequently used being vitamin and mineral supplements (VMSs; 47.8\%) and homoeopathic medicines the least used (6.8\%). A majority of respondents using CM products were also using pharmaceutical products, and small but significant associations were found between the use of CM products and pharmaceuticals $(p<0.05)$. Small statistically significant associations were found between use of vitamin products and disclosure of use to general practitioners (GPs; Cramer's V=0.13, $p=0.004$ ) and hospital doctors (Cramer's V $=0.11, p=0.04$ ), and between use of herbal medicines and disclosure to both GPs (Cramer's V $=0.11, p=0.02$ ) and hospital doctors (Cramer's $\mathrm{V}=0.12, p=0.03$ ). Women, those with higher education and those with no private health insurance were more likely to use CM products $(p<0.05)$, while those without chronic conditions were less likely to use CM products $(p<0.05)$ $\left(\chi^{2}(29)=174.70, p<0.001\right)$.

Conclusions The number of Australians using CM products has remained relatively stable and substantial for nearly two decades. The majority of CM use relates to VMSs. Given the number of Australians using both CM products and pharmaceutical medicines, it is important to evaluate the potential clinical implications of such practices to ensure safe, effective and coordinated health policy and patient care.

\section{INTRODUCTION}

The use of natural products-a range of products not traditionally associated with the medical profession or medical
Strengths and limitations of this study

- This study involves a large sample of adults who were representative of the Australian population for age, gender and demographic location.

- The questionnaire includes validated instruments that are widely used to measure health status.

- The prevalence of complementary medicine (CM) recommendations by Australian healthcare professionals are captured.

- Due to the cross-sectional design, we could not determine causal relationships with $\mathrm{CM}$ use.

- The data are at risk of recall bias based on participant self-report of items related to the previous 12 months.

curriculum-is substantial across most countries. ${ }^{12}$ The titles employed to refer to such products vary between countries depending on the respective regulatory frameworks for medicines and food. The title 'food supplements' is used in the UK, 'traditional herbal medicine' and 'health supplements' in China and parts of South and South East Asia, and the title 'complementary medicines' (CMs) is used in Australia. The Australian Department of Health is responsible for the regulation of CMs in Australia which includes vitamin and mineral supplements (VMSs), herbal and botanical medicines, homoeopathic preparations and aromatherapy oils. We have included all these elements in our definition of CMs to reflect this wider Australian context. $^{3}$

It is important to note that the practices and products that constitute CM may differ within different regions. These differences are considered within the WHOs definition that states "The terms "complementary medicine" or "alternative medicine" refer to a broad set of healthcare practices that are not part of that country's own tradition 
or conventional medicine and are not fully integrated into the dominant healthcare system'. ${ }^{4}$ This definition has been adopted in this study and accommodates a plethora of CM prescribing scenarios and contexts involving different health professionals including doctors and pharmacists. ${ }^{4-6}$ Furthermore, the prescription and recommendation of CMs including vitamins by doctors and pharmacists in the Australian context is not systematic or formally directed ${ }^{78}$ nor is it included in any substantial way in the medical curriculum of any Australian medical school. ${ }^{7}$ In line with this definitional approach, cultural context and previous Australian studies, ${ }^{9-12}$ we have appropriately included vitamins in our CM definition. Importantly, our inclusion of vitamins in our CM definition is in keeping with the Australian health regulatory framework for $\mathrm{CM}^{3}{ }^{3}$

According to a Roy Morgan report, Australian consumers spent over $\$$ AU550 per capita on CMs in 2016 , which was an increase from $\$ A U 472$ from the previous 5 years. ${ }^{13}$ A 2009 study identified $43.6 \%$ of 4500 Australians over the age of 50 years as consuming at least one $\mathrm{CM}$ product in the previous 24-hour period, and of these, $86 \%$ were currently being treated with pharmaceutical medicines. ${ }^{10}$ More recent data show Australians spend more out of pocket contribution to CM products than to pharmaceutical medicines. ${ }^{14}$ Although very dated, the 'latest' peer-reviewed published data obtained from a nationally representative sample of Australians estimated that the annual $\mathrm{CM}$ product expenditure was $\mathrm{A} \$ 1.86$ billion (US $\$ 1.41$ billion) on CMs (excluding practitioner visits) ${ }^{9}$

People use CM products as part of their self-care and make informed decisions about their use. ${ }^{215}$ However, reports suggest that a potentially substantial portion of people living with serious health conditions do not tell their medical doctors about their CM use. ${ }^{16-18}$ Reasons provided for not disclosing CM use are as follows: they did not think it is relevant, that CM practices and products are safe, the doctor would not know about CM and/ or that they would be negatively judged for choosing to use CM. ${ }^{16-18}$

Representative surveys of Australian adults use of CMs are over a decade old rendering the frequently cited prevalence, sociodemographic and economic data as possibly no longer accurate and in some cases obtained from narrow sample populations. ${ }^{919}$ In addition, there is limited current data about the health of Australians who are taking CM products and their decisions to disclose their CM product use to healthcare practitioners. ${ }^{2}$

In response, the study reported in this paper aimed to provide a contemporary analysis of CMs use (including VMSs) drawn from a representative sample of the Australian adult population. The primary objective of this study was to evaluate the prevalence and types of CM products used and the predictors of use.

\section{METHODS}

\section{Study design}

A cross-sectional online survey was administered to 2025 Australian adults representative of the Australian population. Representativeness was defined as matching the study sample population for distribution by age, gender and state of residence against the Australian Bureau of Statistics population demographic data.

\section{Recruitment}

Purposive convenience sampling was used to recruit participants from an existing database of Australian adults who had expressed interest in participating in research (Qualtrics). An email invitation to participate in the study was sent to members of the database. The survey took approximately $15 \mathrm{~min}$ to complete, and participants received a small financial remuneration based on time to complete. Ethics approval was provided by the Human Research Ethics Committee at Endeavour College of Natural Therapies (20170242) in accordance with the Declaration of Helsinki.

\section{Patient and public involvement}

This research was done without substantial patient involvement. Individuals without a research or healthcare background who were known to the research team were invited to comment on the survey instrument but not the study design and they were not consulted to develop patient-relevant outcomes or interpret the results. Patients were not invited to contribute to the writing or editing of this document for readability or accuracy. Patients will be enlisted for their help in the dissemination of the outcomes of this study.

\section{Measurement}

Demographic questions included gender, age, marital status, postcode of residence, highest level of educational qualification, employment status and level of financial difficultly currently experienced. Participants were also asked if they currently had a centre link (social security) healthcare card, and if they had private health insurance for a range of health services.

\section{Health status}

Participants were asked to indicate if they had been diagnosed or treated for a chronic illness in the previous 3 years from a list of 30 chronic conditions, with the option to indicate an 'other health condition' and specify the condition, or 'none of the above' indicating they had not been diagnosed or treated for a chronic illness. One item from the Medical Outcomes Study Short Form-20 (SF-20) was used to assess perceived general health status that asked participants to rate their health status on a 5-point Likert scale ranging from excellent (1) to poor (5). The SF-20 is a widely used measure of health-related quality of life. ${ }^{20}$

CM use

Questions related to CM use were adapted from the International Complementary and Alternative Medicine 
Questionnaire (I-CAM-Q). The I-CAM-Q was developed as a measure of $\mathrm{CM}$ health service and treatment use that could be used consistently across different populations that has been validated in a range of population samples. ${ }^{21}{ }^{22}$ The I-CAM-Q necessitates country-specific items be added that are relevant to the population studied $^{23}$; therefore, a number of changes were made to ensure validity of the I-CAM-Q in an Australian population. Items from the I-CAM-Q used in this study related to $\mathrm{CM}$ product use including products used in the previous 12 months, who prescribed them (eg, type of health practitioner), and estimated total cost of each medicine type.

\section{Pharmaceutical medicine use}

A single item asked participants 'Do you take prescription medicine daily?' requiring a dichotomous (yes, no) response. If answering yes to this question, participants were then asked: 'What condition is the medicine taken to treat?' requiring an open-ended response.

\section{CM disclosure}

Participants were questioned about their communication with healthcare professionals (HCPs) within the previous 12 months. Specifically, they were questioned regarding their disclosure of $\mathrm{CM}$ use to their general practitioner (GP), specialist doctor, hospital doctor and/or pharmacist. There were four response options: 'I told them about ALL complementary and alternative medicines I was using', 'I only told them about SOME of my complementary and alternative medicine use', 'I DID NOT tell them about my complementary and alternative medicine use' and 'I did not visit this type of health professional'.

\section{Data analysis}

The data were analysed using IBM SPSS Statistics Premium Edition V.22. The data were initially screened for disengaged and missing responses, which resulted in six respondents being removed as their responses were unreliable (ie, no variance or repeat patterns in the data), leaving 2019 participants in the final data set. Relevant variables were recoded to reflect a positive direction.

$\chi^{2}$ tests were used to examine the associations between categorical variables of interest and CM product use. Sociodemographic variables with an association $p<0.25^{24}$ or with theoretical importance were included in a logistic regression to identify significant predictors of $\mathrm{CM}$ product use.

Economic data were calculated based on the mean (and $\mathrm{SD}$ ) of expenditure of $\mathrm{CM}$ products for all participants, and for CM product users only. The mean for all participants was then extrapolated to the Australian population based on the most recent census figures. ${ }^{25}$

\section{RESULTS}

\section{Participant characteristics}

The sociodemographic characteristics of participants are included in table 1 . The majority of participants were women ( $\mathrm{n}=1034)$, with three people identifying as 'other' gender, which is comparable to the Australian general population. $^{25}$ The majority of participants $(26.1 \%)$ were $\geq 60$ years of age. New South Wales $(29.7 \%)$ was the most common place of residence. The minority of participants were those aged between 50 and 59 years $(15.2 \%)$ and those residing in the Australian Capital Territory $(1.4 \%)$. The majority of participants were either employed full time $(31.6 \%)$ or not in the paid workforce $(34 \%)$. The most commonly reported highest level of education was a trade/apprenticeship/certificate/diploma (33.8\%), with the least common being less that year 12 (16.2\%). Most participants were married (42.8\%), which compared with $1.4 \%$ in a same-sex and $10.9 \%$ in an opposite-sex de facto relationship.

\section{Associations between sociodemographic variables and CM product use}

$\chi^{2}$ tests of association revealed that gender, employment status, marital status, chronic health condition and private health insurance were all statistically significantly associated with CM product use with (see table 1 for summary statistics). People with private health insurance (PHI) were less likely to use CM products than those without. Cramer's V showed that the strength of all significant associations was negligible $(0.01)$ to small (16). ${ }^{26}$

\section{Expenses for each type of medicine use}

Table 2 presents the summary of the expenditure of each type of medicine product reported in the previous 12 months. Survey respondents spent an average of AUD $\$ 102.41$ on prescription-only pharmaceuticals and $\$ 39.52$ on over-the-counter pharmaceuticals. Mean expenditure on CM products varied across categories with the highest spend on VMSs (AUD\$86.24 per CM product user) and the lowest spend on homeopathy (AUD $\$ 7.05$ per CM product user) and flower essences (AUD $\$ 4.94$ per CM product user). Extrapolation of this data to the Australian population indicates an annual spend of AUD $\$ 480$ on CM products.

\section{Prevalence of $\mathrm{CM}$ and pharmaceutical medicine use and source of prescription}

A total of 1016 participants used any type of CM product (50.3\%), which compared with $74.4 \%$ of participants who used prescription pharmaceuticals, and $66.8 \%$ who used over-the-counter pharmaceuticals. VMSs were the most frequently used CM product (47.8\%) by participants, and were the most frequently prescribed by all types of health practitioners, and the most frequently self-prescribed. In contrast, homeopathic products were the least frequently used $(6.8 \%)$, and the least frequently prescribed CM product by GPs, pharmacists, store assistants and least frequently self-prescribed. See table 3 for a summary of the frequency of each type of medicine use.

Table 3 shows that statistically significant associations were found between all types of medicine use with all sources of medicine prescription. For self-prescription, 
Table 1 Participant sociodemographic characteristics and associations between CM product use

\begin{tabular}{|c|c|c|c|c|}
\hline \multirow[b]{2}{*}{ Characteristic } & \multicolumn{2}{|c|}{ Used CM products } & \multirow{2}{*}{$\begin{array}{l}\text { Total } \\
(\mathrm{N}=2019)\end{array}$} & \multirow[b]{2}{*}{ P value } \\
\hline & No $(n=1003)$ & Yes $(n=1016)$ & & \\
\hline \multicolumn{5}{|l|}{ Gender } \\
\hline Female & $444(44.4)$ & $590(58.1)$ & $1034(51.2)$ & $<0.001$ \\
\hline Male & $557(55.6)$ & 425 (41.9) & $982(48.6)$ & \\
\hline Other* & - & - & $3(0.1)$ & \\
\hline
\end{tabular}

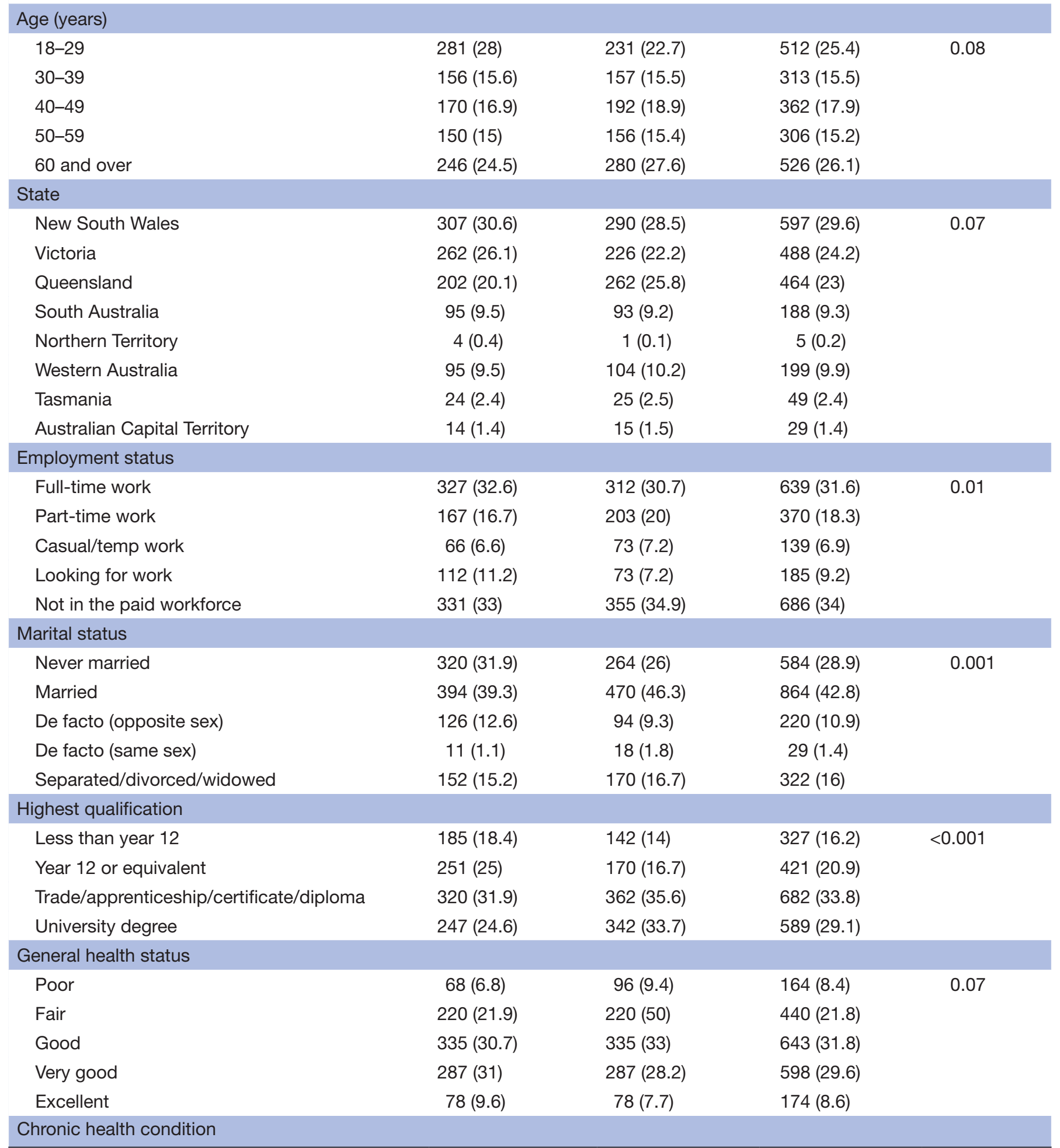

Continued 
Table 1 Continued

\begin{tabular}{|c|c|c|c|c|}
\hline \multirow[b]{2}{*}{ Characteristic } & \multicolumn{2}{|c|}{ Used CM products } & \multirow{2}{*}{$\begin{array}{l}\text { Total } \\
(\mathrm{N}=2019)\end{array}$} & \multirow[b]{2}{*}{$P$ value } \\
\hline & No $(n=1003)$ & Yes $(n=1016)$ & & \\
\hline Yes & $576(57.4)$ & $738(72.6)$ & $1314(65.1)$ & $<0.001$ \\
\hline \multicolumn{5}{|l|}{ Financial management } \\
\hline It is impossible/it is difficult all of the time & $217(21.6)$ & $213(21)$ & $430(21.3)$ & 0.91 \\
\hline It is not too bad & $352(35.1)$ & $348(34.3)$ & $700(34.7)$ & \\
\hline It is easy & $59(5.9)$ & $64(6.3)$ & $123(6.1)$ & \\
\hline \multicolumn{5}{|l|}{ Healthcare card } \\
\hline Yes & $406(40.5)$ & $433(42.6)$ & $839(41.6)$ & 0.34 \\
\hline No & $597(59.5)$ & $583(57.4)$ & $1180(58.4)$ & \\
\hline No & $445(44.4)$ & $546(53.7)$ & $991(49.1)$ & \\
\hline
\end{tabular}

${ }^{*}$ Excluded due to cell size count $<5$.

the strongest associations were found with aromatherapy oils (Cramer's V $=0.58, \mathrm{p}<0.001$ ) and vitamins and mineral use (Cramer's V $=0.61, \mathrm{p}<0.001)$. Unsurprisingly, the strongest association for prescription pharmaceutical use was with GPs (Cramer's V=0.72, $\mathrm{p}<0.001$ ). The weakest association was found between use of over-the-counter pharmaceuticals and CM practitioner prescription (Cramer's $\mathrm{V}=0.06, \mathrm{p}=0.009$ ).

\section{Associations between $\mathrm{CM}$ product use and pharmaceutical} medicine use

The majority ( $>80 \%$ ) of ingestible CM product (ie, herbal medicines, vitamin and nutritional supplements, homeopathy, flower essences) users reported use of pharmaceutical medicines. All types of ingestible CM products were statistically significantly $(\mathrm{p}<0.05)$ associated with both over-the-counter and prescribed pharmaceutical medicine use, with the exception of the relation between flower essences and prescribed pharmaceuticals. The strength of associations ranged from negligible to small. See table 4 for $\chi^{2}$ test results.

\section{CM use disclosure}

$\chi^{2}$ tests of association were conducted between the use of each type of ingestible CM product and disclosure of use to health professionals to determine frequencies and percentages in people who used any type of CM product $(n=1016)$. These analyses only found small statistically significant associations between the use of vitamin/nutritional products and disclosure to both GPs (Cramer's

Table 2 Expenditure for each type of medicine use in the previous 12 months

\begin{tabular}{|c|c|c|c|c|}
\hline Type of medicine used & $\begin{array}{l}\text { Total expenses } \\
(2016-2017)\end{array}$ & $\begin{array}{l}\text { Mean expense } \\
\text { per } \\
\text { CM product user } \\
(n=1016)\end{array}$ & $\begin{array}{l}\text { Mean expense per } \\
\text { person }(n=2019)\end{array}$ & $\begin{array}{l}\text { Estimated CM product } \\
\text { expense for Australian } \\
\text { population ( } n=24702 \\
900 \text { ) }\end{array}$ \\
\hline \multicolumn{5}{|l|}{ Pharmaceutical products } \\
\hline Prescription-only pharmaceuticals & $\$ 206761.69$ & $\$ 122.44$ & $\$ 102.41$ & $\$ 3024623076$ \\
\hline Over-the-counter pharmaceuticals & $\$ 79798.05$ & $\$ 52.39$ & $\$ 39.52$ & $\$ 1294184931$ \\
\hline \multicolumn{5}{|l|}{ CM products } \\
\hline Western or Chinese herbal medicines & $\$ 11534.00$ & $\$ 11.24$ & $\$ 5.71$ & $\$ 277660596$ \\
\hline Vitamin/mineral supplements & $\$ 88297.20$ & $\$ 86.46$ & $\$ 43.73$ & $\$ 2135812734$ \\
\hline Aromatherapy oils & $\$ 10381.00$ & $\$ 10.13$ & $\$ 5.14$ & $\$ 250240377$ \\
\hline Homeopathy & $\$ 7239.00$ & $\$ 7.05$ & $\$ 3.59$ & $\$ 174155445$ \\
\hline Flower essences & $\$ 5107.00$ & $\$ 4.94$ & $\$ 2.54$ & $\$ 122032326$ \\
\hline Total CM products & $\$ 122558.20$ & $\$ 119.82$ & $\$ 60.71$ & $\$ 2959901478$ \\
\hline
\end{tabular}

$\mathrm{CM}$, complementary medicine. 


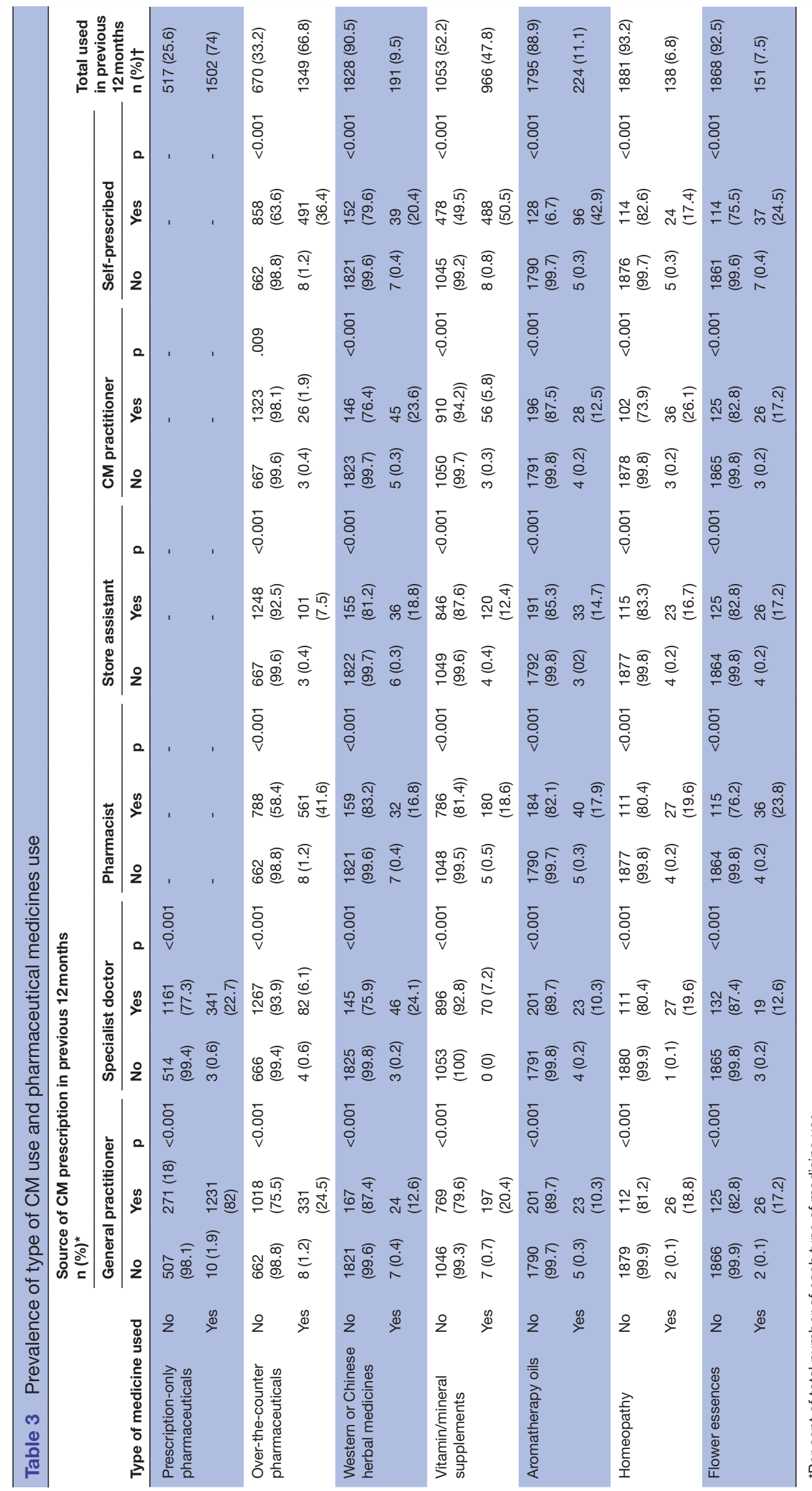


Table 4 Associations between type of ingestible CM product used and pharmaceutical product use

\begin{tabular}{|c|c|c|c|c|c|c|c|c|c|c|c|}
\hline & & \multicolumn{10}{|c|}{ Used any CM product $(n=1016)$} \\
\hline & & \multicolumn{5}{|c|}{ Used prescribed pharmaceutical $n(\%)$} & \multicolumn{5}{|c|}{ Used over-the-counter pharmaceutical n (\%) } \\
\hline \multicolumn{2}{|c|}{$\begin{array}{l}\text { Type of CM product } \\
\text { used }\end{array}$} & No & Yes & Total* $^{*}$ & $\mathbf{p}$ & $\begin{array}{l}\text { Cramer's } \\
\text { V }\end{array}$ & No & Yes & Total $^{*}$ & $\mathbf{p}$ & $\begin{array}{l}\text { Cramer's } \\
\text { V }\end{array}$ \\
\hline \multirow{2}{*}{$\begin{array}{l}\text { Western or } \\
\text { Chinese herbal } \\
\text { medicines }\end{array}$} & No & $151(87.8)$ & $674(79.9)$ & $825(81.2)$ & 0.02 & 0.08 & $181(21.9)$ & $644(78.1)$ & $825(81.2)$ & 0.002 & 0.10 \\
\hline & Yes & $21(12.2)$ & $170(89)$ & $191(18.8)$ & & & $23(12)$ & $168(88)$ & $191(18.8)$ & & \\
\hline $\begin{array}{l}\text { Vitamin/mineral } \\
\text { supplements }\end{array}$ & No & $15(30)$ & $35(70)$ & $50(4.9)$ & 0.01 & 0.08 & $19(38)$ & $31(62)$ & $50(4.9)$ & 0.001 & 0.10 \\
\hline \multirow[t]{2}{*}{ Homeopathy } & No & $160(18.2)$ & $718(81.8))$ & $878(86.4)$ & 0.006 & 0.09 & $199(22.7)$ & 679 (77.3) & $878(86.4)$ & $<0.001$ & 0.16 \\
\hline & Yes & $12(8.7)$ & $126(91.3)$ & $138(13.6)$ & & & $5(3.6)$ & $133(96.4)$ & $138(13.6)$ & & \\
\hline \multirow[t]{2}{*}{ Flower essences } & No & $153(17.7)$ & 712 (82.3) & $865(85.1)$ & 0.12 & 0.05 & $195(22.5)$ & $670(77.5)$ & $865(85.1)$ & $<0.001$ & 0.15 \\
\hline & Yes & $19(12.6)$ & $132(87.4)$ & $151(14.9)$ & & & $9(6)$ & $142(94)$ & $151(14.9)$ & & \\
\hline
\end{tabular}

${ }^{*}$ Percentage of total number of participants using any $\mathrm{CM}$ product. $\mathrm{CM}$, complementary medicine.

$\mathrm{V}=0.13, \mathrm{p}=0.004)$ and hospital doctors (Cramer's $\mathrm{V}=0.11$, $\mathrm{p}=0.04)$, and between use of herbal medicines and disclosure to both GPs (Cramer's V=0.11, $\mathrm{p}=0.02$ ) and hospital doctors (Cramer's V=0.12, $\mathrm{p}=0.03$ ). No association was found between any other type of product use and disclosure to health practitioners. See table 5 for summary statistics.

\section{Predictors of CM product use}

The independent variables of gender, age, marital status, qualification, general health status, chronic health condition and private health insurance were included in a binomial logistic regression predicting $\mathrm{CM}$ product use. The model was statistically significant, $\chi^{2}(29)=174.70, \mathrm{p}<0.001$, and correctly classified $61 \%$ of cases. Gender, qualification, chronic disease diagnosis and private health insurance were statistically significant $(\mathrm{p}<0.05)$ predictors of CM product use (see table 6). Women had an increased odds of using CM product compared with men. Higher education levels were associated with an increased likelihood of CM product use compared with those with less than year 12 level education, with the exception of university degree level. People with a chronic health condition were more likely to use CM products compared with those without a chronic health condition. Those without private health insurance were more likely to use CM products compared with those with PHI.

\section{DISCUSSION}

This is the first study in over a decade to report the prevalence, characteristics and predictors of CM product use in a nationally representative population of Australians. We identified that $50.3 \%$ of Australians used some form of $\mathrm{CM}$ product in the previous 12 months. CM use in the general population has previously reported in 2006 at $68.9 \%$ including both products and services. ${ }^{9}$ Unfortunately, a direct comparison between our data and this previous study cannot be made as a number of CM in the older study could not be clearly categorised into either products or services. The consistency of these figures suggests that the use of CM products is an established feature of Australians' healthcare choices.

The estimated annual expenditure on CM products by the adult Australian population in 2006 was $\mathrm{A} \$ 1.86$ billion, ${ }^{9}$ which is higher than the estimated expenditure of AUD $\$ 480$ million identified from our data. It is important to note, however, that the difference in expenditure is likely related to the difference in defining a $\mathrm{CM}$ product rather than a substantive difference in CM spending by the Australian population. As the previously published data did not specify which products were included in the final amount of expenditure, the variability between both studies is difficult to meaningfully quantify. Industry data from the Complementary Medicine Association for CM reports much higher sales revenue for CM products (AUD \$4.7 billion); however, this includes domestic sales and international exports as well as other health products not included in our study, such as sports nutrition, meal replacements and weight loss products. ${ }^{27}$

VMSs were the most common CM product used by Australians (47\%), which is comparable to $45 \%$ of Australians who reported using supplements in $2006 .{ }^{9}$ Other reports obtained from narrower samples of Australians within the last 20 years provide similar rates, reporting VMS use ranging from $47 \%$ to 53\%. ${ }^{10} 192829$ Both Xue et $a t^{\ominus}$ and Morgan $e t a l^{10}$ instructed participants to exclude medically prescribed nutrients such as iron and calcium when reporting their VMS use. This present study did not instruct participants to exclude medically prescribed nutrients. Nevertheless, VMS were the most common CM products prescribed by any type of healthcare professional in our study, which may be associated with the treatment of common medical conditions such as iron deficiency, ${ }^{30}$ the use of calcium and vitamin $\mathrm{D}$ in the clinical management of osteoporosis, vitamin D deficiency ${ }^{31}$ and specific VMS formulations for macular degeneration. ${ }^{32} 33$ 


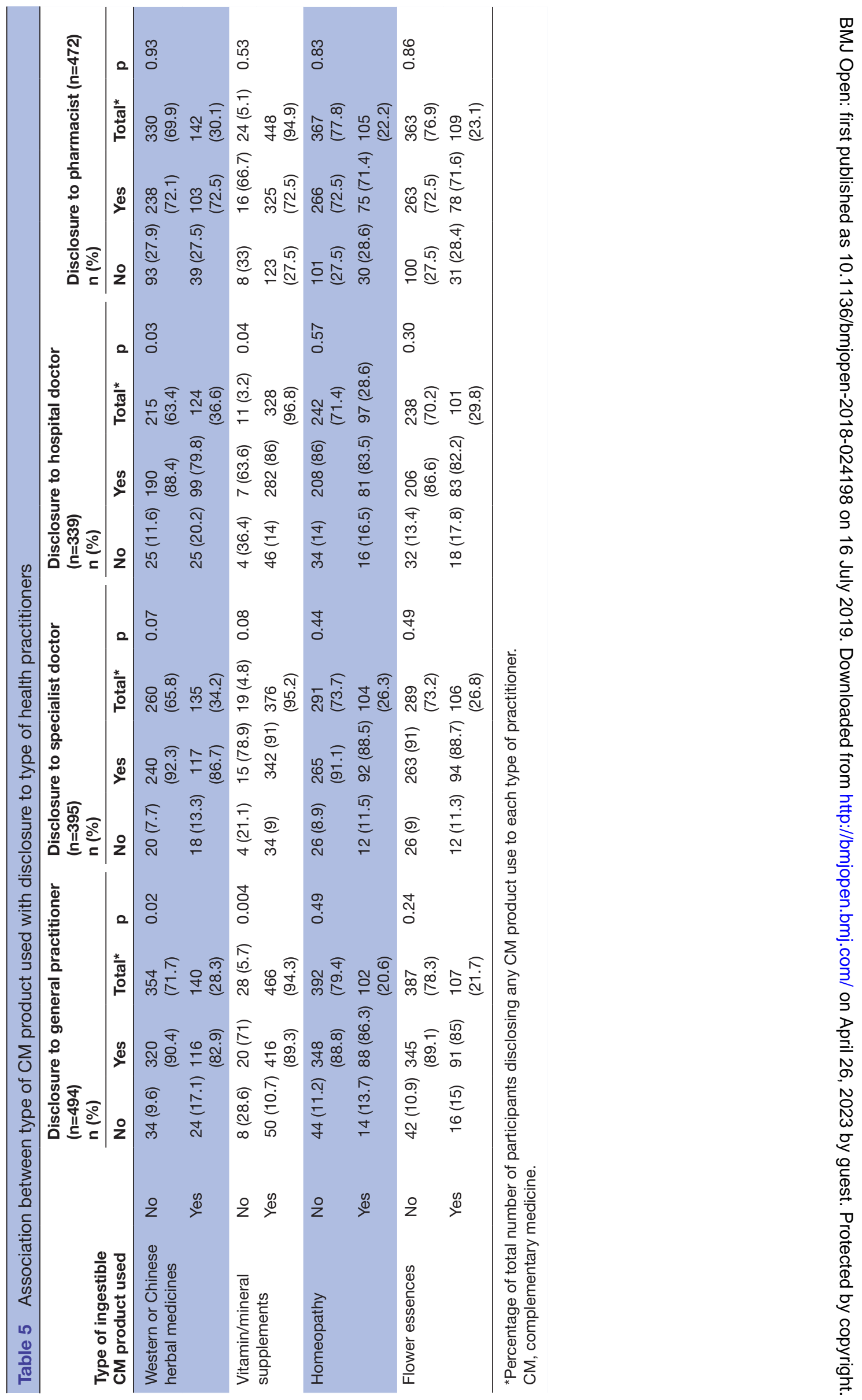


Table 6 Predictors of complementary medicine product use

\begin{tabular}{|c|c|c|}
\hline Variable & OR $(95 \% \mathrm{Cl})$ & $P$ value \\
\hline \multicolumn{3}{|l|}{ Gender } \\
\hline Female & 1.78 (1.46 to 2.18$)$ & $<0.001$ \\
\hline Male & - & - \\
\hline \multicolumn{3}{|l|}{ Age (years) } \\
\hline $18-29$ & - & 0.55 \\
\hline $30-39$ & 0.83 (0.59 to 1.17$)$ & 0.29 \\
\hline $40-49$ & 0.80 (0.57 to 1.13$)$ & 0.21 \\
\hline $50-59$ & 0.87 (0.63 to 1.19$)$ & 0.38 \\
\hline 60 and over & 0.76 (0.56 to 1.06$)$ & 0.10 \\
\hline \multicolumn{3}{|l|}{ State } \\
\hline New South Wales & - & 0.21 \\
\hline Victoria & 0.87 (0.40 to 1.92$)$ & 0.73 \\
\hline Queensland & 0.77 (0.35 to 1.71$)$ & 0.52 \\
\hline South Australia & 1.12 (0.50 to 2.48$)$ & 0.79 \\
\hline Northern Territory & 0.92 (0.40 to 2.12 ) & 0.85 \\
\hline Western Australia & 0.23 (0.02 to 2.54$)$ & 0.23 \\
\hline Tasmania & 1.02 (0.45 to 2.33$)$ & 0.96 \\
\hline Australian Capital Territory & 0.93 (0.35 to 2.48$)$ & 0.89 \\
\hline \multicolumn{3}{|l|}{ Employment status } \\
\hline Full-time work & - & 0.13 \\
\hline Part-time work & 1.08 (0.81 to 1.43$)$ & 0.61 \\
\hline Casual/temp work & 1.25 (0.93 to 1.68$)$ & 0.14 \\
\hline Looking for work & 1.18 (0.79 to 1.78$)$ & 0.42 \\
\hline Not in the paid workforce & 0.76 (0.52 to 1.10$)$ & 0.15 \\
\hline \multicolumn{3}{|l|}{ Marital status } \\
\hline Never married & - & 0.18 \\
\hline Married & 0.95 (0.68 to 1.33$)$ & 0.77 \\
\hline De facto (opposite sex) & 1.07 (0.81 to 1.42$)$ & 0.61 \\
\hline De facto (same sex) & 0.73 (0.50 to 1.07$)$ & 0.11 \\
\hline Separated/divorced/widowed & 1.43 (0.62 to 3.32$)$ & 0.40 \\
\hline \multicolumn{3}{|l|}{ Highest qualification } \\
\hline Less than year 12 & - & $<0.001$ \\
\hline Year 12 or equivalent & 0.53 (0.39 to 0.73$)$ & $<0.001$ \\
\hline Trade/apprenticeship/certificate/diploma & 0.51 (0.39 to 0.68$)$ & $<0.001$ \\
\hline University degree & 0.81 (0.63 to 1.05$)$ & 0.09 \\
\hline \multicolumn{3}{|l|}{ General health status } \\
\hline Poor & - & 0.31 \\
\hline Fair & 1.40 (0.86 to 2.26$)$ & 0.18 \\
\hline Good & 0.96 (0.65 to 1.41$)$ & 0.84 \\
\hline Very good & $1.12(0.78$ to 1.61$)$ & 0.53 \\
\hline Excellent & 0.99 (0.69 to 1.42$)$ & 0.95 \\
\hline \multicolumn{3}{|l|}{ Chronic health condition } \\
\hline No & 0.52 (0.42 to 0.64$)$ & $<0.001$ \\
\hline Yes & - & - \\
\hline
\end{tabular}




\begin{tabular}{llc}
\hline Table 6 Continued & & P value \\
\hline Variable & OR $(95 \% \mathbf{~ C l})$ & 0.01 \\
\hline No & $1.33(1.09$ to 1.62$)$ & - \\
Yes & - & 0.57 \\
Constant & 1.30 &
\end{tabular}

As reported by the participants in this study, VMS were the most commonly prescribed $\mathrm{CM}$ products by all healthcare providers, half of the VMS used were self-prescribed. It is generally accepted and promoted by health authorities and health professionals, that eating a well-balanced diet will provide adequate vitamin and minerals to prevent deficiencies. ${ }^{34}$ VMSs sold in Australia are required to carry a 'warning' on their labels that reads 'vitamin/ mineral supplements should not replace a balanced diet'. Although the reasons why so many Australians use VMSs was not the focus of this study, it is important that additional research is conducted to identify drivers of VMS use. Possible reasons for such high use may be associated with the substantial number of Australians not meeting the recommended intake of foods high in vitamins and minerals and their high intake of 'discretional' foods. ${ }^{35}$ The Australian Bureau of Statistics 2015 National Health Survey reported that just less than half $(49.8 \%)$ of Australian adults meet the Australian Dietary Guidelines for recommended daily serves of fruit, only $7 \%$ meet the guidelines for serves of vegetables, and $5.1 \%$ meet both guidelines. ${ }^{35}$ Other research has reported inadequate dietary intakes and/or deficiencies of specific nutrients among children, pregnant women and adolescences for iron $^{30}$ zinc, $^{36}$ calcium, magnesium, vitamin $\mathrm{D}$ and folic acid. ${ }^{37}$ Whether the high use of VMS among Australians is associated with an attempt to compensate for poor food choices is an area that requires public health attention. Of equal importance, is the need to understand if and why well-nourished Australians supplement their diet with VMSs. While there is some evidence to suggest that the long-term use of multi-VMSs for up to 10 years in healthy populations is likely to be safe, formulations vary and there are safety concerns for specific populations taking specific nutrients; for example, smokers and beta carotene use has been associated with increasing the risk of lung cancer. ${ }^{38}$ Other research is currently being conducted to evaluate the efficacy and safety of more clearly defined VMS formulations in specific populations. ${ }^{39}$

$\mathrm{CM}$ product use being greater among women, those in full-time employment, and those with a higher level of education in our study is consistent with previous findings. ${ }^{2929}$ However, our finding that those with private health insurance were less likely to use CM products compared with those with private health insurance differs from these previous studies. ${ }^{929}{ }^{40}$ While highly speculative, there may be an association with the rising costs of private health insurance premiums in Australia ${ }^{41}$ and consumers allocating more of their income on health maintenance and preventative strategies as a 'surrogate' to private health insurance. The efficacy of VMS in disease prevention and health maintenance is unclear and controversial resulting in large-scale research currently being undertaken. ${ }^{39}$

Having a diagnosis of one or more chronic illnesses also increased the likelihood of CM product use and CM product users were likely $(>80 \%)$ users of both over-thecounter and prescription pharmaceuticals. Given that self-prescribing of CM products is the most common method leading to use, it is important that healthcare professionals caring for individuals with chronic disease inquire about CM product use and monitor for any potential disease-CM interactions and drug-CM product interactions, especially with regards to herbal medicines. The likelihood of having a chronic illness increases with age and so does pharmaceutical medicine use. ${ }^{10}$ While evidence-based resources aimed at practitioners are available to guide appropriate and safe use of $\mathrm{CMs},{ }^{42}$ well-established evidence based on human studies is limited. Available evidence is largely based on theory obtained from animal studies with individual case reports currently used to calculate likely risks. ${ }^{43}$ This being said, it is well established that short-acting pharmaceutical medicines used for serious diseases, such as the use of digoxin for heart disease and chemotherapeutic agents for cancer, may result in serious interactions when used concurrently with some CMs, resulting in possible therapeutic failure or drug-related toxicity. ${ }^{44}$

The finding that both users of VMS and herbal medicines were more likely to disclose their use to their GPs and hospital doctors than to pharmacists and specialists is encouraging. However, overall the number of those that never disclose their herbal medicine use $(18 \%)$ is similar to that reported in 2006 where $17.9 \%$ participants never informed their doctors about any CM use. ${ }^{9}$ However, data obtained in 2012 reporting Australians' disclosure to HCPs about CM use reported that only $47 \%$ to $60 \%$ informed their health professionals. ${ }^{45}$

Given the majority of $\mathrm{CM}$ products and over-the-counter pharmaceutical and prescription medicines are accessed through pharmacy outlets, further developments within the profession are required to help encourage $\mathrm{CM}$ product users to discuss such use with their pharmacist. ${ }^{8}$ The reasons for a lower disclosure rate about CM use to medical specialists and pharmacists compared with other healthcare professionals in this study is unclear. Speculatively, there may be an association with earlier reports that suggest such healthcare providers feel they do not have adequate training or education to be able to engage in discussions about CMs. 7164647 
This study presents the first nationally representative data in over 10 years regarding the use of CM products in the Australian population. Interpretation of the findings, however, must be contextualised to the study's limitations. The study may be vulnerable to random error due to sampling bias; however, as the participants have been verified as nationally consistent based on a range of sociodemographic variables, this is likely to have minimal impact on the outcome of our analysis. The data are also at risk of recall bias based on participant self-report of items related to the previous 12 months. This is particularly the case for the economic data, which should only be considered estimates of true values. However, the instrument used in this study is informed by increased rigour in health services research methodology and advances in knowledge regarding CM use globally over the last decade, and as such offers the most robust and contemporary view of the topic than has been available in recent years.

\section{CONCLUSIONS}

Overall CM product use in Australia has remained stable over the last 10 years and can be confirmed as an established component of many Australians healthcare choices. This highlights the need for all health professionals providing care to the Australian population to engage more meaningfully in the role, value and implications of this use. Pharmacists and medical doctors, in particular, need to ensure their knowledge of ingestible CM products is up-to-date and evidence-based so they can provide accurate and relevant information to the Australian community seeking their care. Future research is encouraged to focus on the reasons a substantial number of Australian are using VMS, the efficacy in 'supplementing' inadequate dietary nutrient intakes and the safety of longterm and concurrent use with pharmaceutical medicines.

\section{Author affiliations}

${ }^{1}$ School of Pharmacy, Faculty of Medicine and Health, The University of Sydney, Sydney, New South Wales, Australia

${ }^{2}$ Faculty of Health, University of Technology Sydney, Sydney, UK

${ }^{3}$ Australian Research Centre in Complementary and Integrative Medicine (ARCCIM), University of Technology Sydney, Sydney, New South Wales, Australia

${ }^{4}$ Endeavour College of Natural Health - Sydney, Sydney, New South Wales, Australia ${ }^{5}$ Faculty of Health, University of Technology Sydney, Sydney, New South Wales, Australia

${ }^{6}$ School of Population Health, University of Queensland, Brisbane, Queensland, Australia

Acknowledgements The authors would like to acknowledge the Australians who participated in this study for the time and effort they have contributed.

Contributors JEH, EMI and AS contributed to the study design and developed the survey instrument. EMI conducted the analysis. DS critically reviewed the analysis. JEH, EMI, AS and HF prepared the manuscript that was critically reviewed by JA and DS.

Funding This study was funded by direct contributions from Endeavour College of Natural Health and the Australian Research Centre in Complementary and Integrative Medicine (University of Technology Sydney). HF was supported by an Australian Government Research Training Program Scholarship while contributing to this manuscript. JA was supported by an Australian Research Council Professorial
Future Fellowship while working on this manuscript (Grant FT140100195). JEH's academic position was supported by a philanthropic donation from Blackmores Pty Ltd during the course of this study.

Competing interests None declared.

Patient consent for publication Not required.

Ethics approval Ethics approval was provided by the Human Research Ethics Committee at Endeavour College of Natural Therapies (20170242) in accordance with the Declaration of Helsinki.

Provenance and peer review Not commissioned; externally peer reviewed.

Data sharing statement All data collected for this study are presented in the manuscript.

Open access This is an open access article distributed in accordance with the Creative Commons Attribution Non Commercial (CC BY-NC 4.0) license, which permits others to distribute, remix, adapt, build upon this work non-commercially, and license their derivative works on different terms, provided the original work is properly cited, appropriate credit is given, any changes made indicated, and the use is non-commercial. See: http://creativecommons.org/licenses/by-nc/4.0/.

\section{REFERENCES}

1. Coulter ID, Willis EM. The rise and rise of complementary and alternative medicine: a sociological perspective. Med J Aust 2004;180:587-90.

2. Reid R, Steel A, Wardle J, et al. Complementary medicine use by the Australian population: a critical mixed studies systematic review of utilisation, perceptions and factors associated with use. BMC Complement Altern Med 2016;16:1-23.

3. The Australian Government,. The Therapeutic Goods Administration, Complementary Medicine Regulation, 2018: Canberra. Australia https://www.tga.gov.au/complementary-medicines (accessed 31st July 2018)

4. The World Health Organisation. WHO traditional medicine strategy: 2014-2023. Geneva Switzerland: World Health Organisation, 2014:76.

5. World Health Organization. Fact sheet $N^{\circ} 134$ : Traditional medicine. http://www.who.int/mediacentre/factsheets/fs134/en/print.html.

6. Adams J, Valery PC, Sibbritt D, et al. Use of Traditional Indigenous Medicine and Complementary Medicine Among Indigenous Cancer Patients in Queensland, Australia. Integr Cancer Ther 2015;14:359-65.

7. Templeman K, Robinson A, McKenna L. Student identification of the need for complementary medicine education in Australian medical curricula: a constructivist grounded theory approach. Complement Ther Med 2015;23:257-64.

8. Ung COL, Harnett J, Hu H. Development of a strategic model for integrating complementary medicines into professional pharmacy practice. Res Social Adm Pharm 2018;14.

9 Xue CC, Zhang AL, Lin V, et al. Complementary and alternative medicine use in Australia: a national population-based survey. $J$ Altern Complement Med 2007;13:643-50.

10. Morgan TK, Williamson M, Pirotta M, et al. A national census of medicines use: a 24-hour snapshot of Australians aged 50 years and older. Med J Aust 2012;196:50-3.

11. MacLennan AH, Myers SP, Taylor AW. The continuing use of complementary and alternative medicine in South Australia: costs and beliefs in 2004. MJA 2006:184.

12. Sibbritt D, Adams J, Lui CW. A longitudinal analysis of complementary and alternative medicine use by a representative cohort of young Australian women with asthma, 1996-2006. J Asthma 2011;48:380-6.

13. Morgan R. Checking the health of Australia's vitamin market. Press Release 2015.

14. The Australian Institute of Health and Welfare. Health Expenditure Australia 2010-2011, Australia. https://www.aihw.gov.au/ (accessed 1stMay 2018).

15. NPS. Complementary medicines: attitudes and information needs of consumers and healthcare professionals In: (NPS) pftNPSL. Australia: NPS, 2007.

16. Sullivan A, Gilbar P, Curtain C. Complementary and Alternative Medicine Use in Cancer Patients in Rural Australia. Integr Cancer Ther 2015;14:350-8.

17. Davis EL, Oh B, Butow PN, et al. Cancer patient disclosure and patient-doctor communication of complementary and alternative medicine use: a systematic review. Oncologist 2012;17:1475-81. 
18. Hunter D, Oates R, Gawthrop J, et al. Complementary and alternative medicine use and disclosure amongst Australian radiotherapy patients. Support Care Cancer 2014;22:1571-8.

19. MacLennan AH, Wilson DH, Taylor AW. The escalating cost and prevalence of alternative medicine. Prev Med 2002;35:166-73.

20. Stewart AL, Hays RD, Ware JE. The MOS short-form general health survey. Reliability and validity in a patient population. Med Care 1988;26:724-35.

21. Quandt SA, Verhoef MJ, Arcury TA, et al. Development of an international questionnaire to measure use of complementary and alternative medicine (I-CAM-Q). J Altern Complement Med 2009;15:331-9.

22. Quandt SA, Ip EH, Saldana S, et al. Comparing Two Questionnaires for Eliciting CAM Use in a Multi-Ethnic US Population of Older Adults. Eur J Integr Med 2012;4:e205-11.

23. Bryden GM, Browne M. Development and evaluation of the R-I-CAM-Q as a brief summative measure of CAM utilisation. Complement Ther Med 2016;27:82-6.

24. Hosmer DW, Lemeshow S. Model-Building Strategies and Methods for Logistic Regression. Applied Logistic Regression: John Wiley \& Sons, Inc, 2005:91-142.

25. Australian Bureau of Statistics. Australian Demographic Statistics. 2017 http://www.abs.gov.au/ (accessed 7th April 2018).

26. Cohen J. A power primer. Psychol Bull 1992;112:155-9.

27. Harnett J, Schloss J, Van de Venter C, et al. The diagnostic and clinical management of individuals recommended gluten free diets by complementary medicine practitioners. Adv Integr Med 2018.

28. MacLennan A, Wilson D, Taylor A. Prevalence and cost of alternative health in Australia. Lancet 1996;2.

29. MacLennan AH, Myers SP, Taylor AW. The continuing use of complementary and alternative medicine in South Australia: costs and beliefs in 2004. Med J Aust 2006;184:5.

30. Pasricha SR, Flecknoe-Brown SC, Allen KJ, et al. Diagnosis and management of iron deficiency anaemia: a clinical update. Med $J$ Aust 2010;193:525-32.

31. Nowson CA, McGrath JJ, Ebeling PR, et al. Working Group of Australian and New Zealand Bone and Mineral Society, Endocrine Society of Australia and Osteoporosis Australia. Vitamin D and health in adults in Australia and New Zealand: a position statement. Med J Aust 2012;196:686-7.

32. Sin HP, Liu DT, Lam DS. Lifestyle modification, nutritional and vitamins supplements for age-related macular degeneration. Acta Ophthalmol 2013;91:6-11.
33. Evans JR, Lawrenson JG. A review of the evidence for dietary interventions in preventing or slowing the progression of age-related macular degeneration. Ophthalmic Physiol Opt 2014;34:390-6.

34. Harvard Medical School,. Vitamins and Minerals Special Health Report, H.D. Sesso, Editor. Boston: Harvard Medical School, 2017.

35. Australian Bureau of Statistics, A.B.S. National Health Survey: First Results 2014-15. 2015 Statistics, A.B.S. National Health Survey: First Results 2014-15, 2015.

36. Ho M, Baur LA, Cowell CT, et al. Zinc status, dietary zinc intake and metabolic risk in Australian children and adolescents; Nepean Longitudinal Study. Eur J Nutr 2017;56:2407-14.

37. Gallagher CM, Black LJ, Oddy WH. Micronutrient intakes from food and supplements in Australian adolescents. Nutrients 2014;6:342-54.

38. Fortmann SP, Burda BU, Senger CA, et al. Vitamin and mineral supplements in the primary prevention of cardiovascular disease and cancer: An updated systematic evidence review for the U.S. Preventive Services Task Force. Ann Intern Med 2013;159:824-34.

39. Blumberg JB, Bailey RL, Sesso HD, et al. The Evolving Role of Multivitamin/Multimineral Supplement Use among Adults in the Age of Personalized Nutrition. Nutrients 2018;10:248.

40. Reid R, Steel A, Wardle J, et al. Complementary medicine use by the Australian population: a critical mixed studies systematic review of utilisation, perceptions and factors associated with use. BMC Complement Altern Med 2016;16:176.

41. Nguyen L, Worthington A. Adverse Selection in Private Health Insurance. Consumer Interests Annual 2017:63.

42. Braun LC, Herbs M. Natural supplements an evidence-based guide. 4th Edition. Australia: Churchill Livingstone Elsevier, 2015. 4th ed.

43. Roufogalis B, Coxeter PD, McLachlan AJ, et al. Herb-drug Interactions: Interaction or Over-reaction? Journal of Complementary Medicine: CM, The 2003;2:60.

44. Mouly S, Lloret-Linares C, Sellier PO, et al. Is the clinical relevance of drug-food and drug-herb interactions limited to grapefruit juice and Saint-John's Wort? Pharmacol Res 2017;118:82-92

45. Thomson P, Jones J, Evans JM, et al. Factors influencing the use of complementary and alternative medicine and whether patients inform their primary care physician. Complement Ther Med 2012;20:45-53.

46. Koh HL, Teo HH, Ng HL. Pharmacists' patterns of use, knowledge, and attitudes toward complementary and alternative medicine. $J$ Altern Complement Med 2003;9:51-63.

47. Ung COL, Harnett J, Hu H. Key stakeholder perspectives on the barriers and solutions to pharmacy practice towards complementary medicines: an Australian experience. BMC Complement Altern Med 2017;17:394 
Correction: Use of complementary medicine products: $a$ nationally representative cross-sectional survey of 2019 Australian adults

Harnett JE, McIntyre E, Steel A, et al. Use of complementary medicine products: a nationally representative cross-sectional survey of 2019 Australian adults. BMJ Open 2019;9:e024198. doi: 10.1136/bmjopen-2018-024198

This article was previously published with errors in data.

The error relates to a discrepancy between the reporting of a dollar amount in Table 2 and the text of the section 'expense of each type of medicine use'.

Incorrect statement: 'Extrapolation of this data to the Australian population indicates an annual spend of AUD $\$ 480$ on CM products.'

Corrected statement: 'Extrapolation of this data to the Australian population indicates an annual spend of AUD\$2 959901478 on CM products.'

Table 2 does not require any revision. The incorrect $\$$ amount is cited again in the discussion section:

'The estimated annual expenditure on CM products by the adult Australian population in 2006 was $\mathrm{A} \$ 1.86$ billion, ${ }^{9}$ which is higher than the estimated expenditure of AUD $\$ 480$ million identified from our data.'

The sentence below has been revised to contain the correct information for inclusion in the discussion:

'The estimated annual expenditure on CM products by the adult Australian population in 2006 was $\mathrm{A} \$ 1.86$ billion, ${ }^{9}$ which is lower than the estimated expenditure of AUD \$2.9 billion identified from our data.'

Open access This is an open access article distributed in accordance with the Creative Commons Attribution Non Commercial (CC BY-NC 4.0) license, which permits others to distribute, remix, adapt, build upon this work non-commercially, and license their derivative works on different terms, provided the original work is properly cited, appropriate credit is given, any changes made indicated, and the use is non-commercial. See: http://creativecommons.org/licenses/by-nc/4.0/

C Author(s) (or their employer(s)) 2019. Re-use permitted under CC BY-NC. No commercial re-use. See rights and permissions. Published by BMJ.

BMJ Open 2019;9:e024198corr1. doi:10.1136/bmjopen-2018-024198corr1

Check for updates 